\title{
Epidemic of Vitamin D Deficiency Among Tea Plantation Women of Assam, India
}

\section{Priyanka Bhattacharyya ${ }^{1 *}$ and Mamoni Das ${ }^{2}$}

${ }^{1}$ PhD Scholar, Department of Food Science and Nutrition, College of Community Science, Assam Agricultural University, Jorhat-13, India ${ }^{2}$ Professor, Department of Food Science and Nutrition, College of Community Science, Assam Agricultural University, Jorhat-13, India

*Corresponding author: priyankabhatta9494@gmail.com (ORCID ID: 0000-0001-5504-3364)

Received: 05-03-2021

Revised: 14-05-2021

Accepted: 07-06-2021

\begin{abstract}
Vitamin D deficiency is rising as a serious public health issue, affecting a major section of the population across the world. Considering the numerous health implications of vitamin D deficiency, it is of dire significance to identify this epidemic and work for its eradication. The women in the tea plantations are among the most vulnerable groups in Assam and are reported to have the highest mortality rate in the state. The present study is conducted to determine the prevalence of vitamin D deficiency among women in the tea plantations of Assam. An attempt is also made to study the factors correlated with the vitamin D status of women. 370 working women are selected from two tea estates of Assam. Serum vitamin D status is assessed. Socio-economic background, morbidity profile, sunning practice, substance (alcohol and tobacco) abuse pattern and dietary intake is obtained through a standard protocol. The prevalence of Vitamin D deficiency is at the rate of 69.50 percent. Vitamin D status of women suffering from disease conditions such as hypertension, diabetes mellitus, cancer, chronic fatigue, and body pain is significantly lower than healthy women. A significant correlation between the vitamin D status and clothing pattern, tobacco and alcohol consumption, and dietary intake of the women is observed. This study extrapolates the urgency to recognize vitamin D deficiency as a serious epidemic prevailing among women. The various factors identified to exaggerate the deficiency need to be brought to light through proper awareness and health education.
\end{abstract}

\section{HIGHLIGHTS}

(0) The impact of vitamin D deficiency is precarious among women residing in tea plantations of Assam.

( Sunning pattern, tobacco and alcohol consumption and dietary intake have been identified as major contributors to the deficiency.

(0 Proper nutrition education and awareness is necessary to reduce the impact of the determinants of the deficiency.

Keywords: Vitamin D, women, tea plantation, tobacco, alcohol, sunning practices, morbidity

Vitamin D is a fat-soluble vitamin that is produced subcutaneously in the human body from 7-dehydrocholesterol after exposure to the ultraviolet light from the sun. Vitamin D plays a vital role in maintaining blood concentrations of calcium and phosphate by facilitating their absorption (Ahasan et al. 2013). Deficiency of vitamin D is known to cause demineralization of bones and other tissue, which manifests as skeletal problems such as osteoporosis and osteomalacia in adults and rickets in children

How to cite this article: Bhattacharyya, P. and Das, M. (2021). Epidemic of Vitamin D Deficiency Among Tea Plantation Women of Assam, India. Int. J. Soc. Sci., 10(02): 133-142.

Source of Support: None; Conflict of Interest: None 
(Forrest et al., 2011). In addition to its role in bone health, vitamin D has several non-skeletal actions on the body, including inhibition of cell proliferation, promotion of cell differentiation, and apoptosis. This, in turn, has significant roles in regulating tissue formation, immunity, and many organ systems (Garg et al. 2014). Vitamin D is also associated with increased risk of metabolic syndromes such as hypertension and diabetes mellitus, autoimmune diseases, cancer, and cardiovascular diseases. The cell is differentiating and immunomodulatory properties of vitamin D make its use in treating psoriasis and other skin diseases (Wacker et al. 2013).. Several epidemiological studies have proven the role of vitamin D supplementation in managing chronic ailments, including cancer, diabetes mellitus, and its complications (Jiang et al. 2016).

Over the past few years, vitamin D deficiency has risen as a global epidemic, with a worldwide prevalence rate of $70-90 \%$. In the $18^{\text {th }}$ workshop on vitamin D deficiency held by the World Health Organisation (WHO) in 2015, vitamin D deficiency was declaredne of the major public health concerns (Choudhary et al. 2017). The world has seen a steep rise in the cases of bone-related disorders among different age groups within the past decade, which indicates a severe pre-disposition of vitamin D deficiency among populations. The devastating trend in the epidemiology of vitamin D, despite increased globalization and health facilities, is a severe threat to humankind (Harsh et al. 2016).

Vitamin D deficiency is reported to be alarmingly high in developing countries of South Asia, including India. Around $60-70 \%$ population in Southeast Asia and 70\% in South Asia are affected by vitamin D deficiency (Lee et al. 2015). Among the developing countries of South Asia, India occupies a larger share of the vitamin D deficient population, where poverty and malnutrition prevail in most society and further exacerbate the magnitude of an epidemic (Daly et al. 2012). South Asian countries are relatively more affected with vitamin D deficiency for certain predominant factors like lifestyle, socio-economic and cultural taboos, genetic factors, and inadequate dietary intake of vitamin D (Hossein et al. 2013).
The recent trend indicates that vitamin D deficiency is increasingly growing among women, particularly in women of reproductive age. Moreover, vitamin D deficiency-induced osteoporosis and osteomalacia is also increasing at an alarming rate, being reported to be a major cause of morbidity in many women (Rattan et al. 2016). Researchers have postulated the existence of vitamin D deficiency among women suffering from non-communicable disorders such as diabetes mellitus, cardiovascular diseases, and cancer, owing to the association of vitamin $\mathrm{D}$ in the regulatory activity in the body (Afzal et al. 2013). The increased number of cases of rickets and other bone deformities among children across the world is another significant indication of poor vitamin $\mathrm{D}$ in maternal nutrition, which hampers the prenatal development of the child (Baidya et al. 2012).

Vitamin D deficiency is mainly attributed to factors that hinder the skin's absorbance of sunlight. Activities that result in inadequate absorbance to the sun, such as staying indoors for prolonged hours during the daytime, using clothing that covers the majority of body parts, and wearing excessive sunscreens or sunblocks throughout the day, are major factors contributing to the growing vitamin D deficiency worldwide (Bawaskar et al. 2017). Vitamin D deficiency in women is also attributed to the nutritional exhaust and metabolic changes that women experience in different physiological stages, particularly during puberty, pregnancy, and lactation (Chirumbolo, 2015).

The women residing in the tea plantations of Assam are highly vulnerable to nutritional deficiencies because of theirpooreconomic, social, andeducationalbackgrounds. The tea community of Assam has been reported to have poor maternal mortality and morbidity for a very long time, results of which are often manifested as high rates of malnutrition and developmental disorders among the children (Borgohain, 2013). Despite the various flagship efforts put forward by both government and non-government organizations, the tea community has not been able to overcome their poor health and living conditions (Gunjaliya et al. 2015). Several studies have been reported on the prevalence of bone-related disorders among tea tribe women and children. Studies have also shown an increasing prevalence of metabolic 
syndromes, including hypertension and other cardiovascular diseases, among the tea community (Baishya, 2016).

The women of the tea community form an essential part of the tea industry. These women have been contributing to the economy and prosperity of the state since time immemorial. From working as daily wage earners in the tea estates to taking care of the family, these women undergo several hardships throughout their life. Hence, it is of utmost importance to work for the betterment of their health and well-being. The present study is planned to determine the prevalence of vitamin $\mathrm{D}$ deficiency among the women working as tea plantation workers in Assam. Through the study, an attempt is also made to find the factors correlated with the vitamin D status of the women.

\section{METHODOLOGY}

370 women (18-40 years) working as tea plantation workers in Panitola and Dinjan tea estate of Assam, India, are selected for the present study. Socio-economic profile, tobacco, alcohol consumption, and sun exposure patternare collected using a standardized questionnaire. Morbidity profile is collected using hospital records obtained from the tea estate hospitals. Dietary intake is obtained using a pre-tested food frequency questionnaire. Serum 1, 25-dihydroxy vitamin $D_{3}$ is assessed using the enzyme immunoassay method and chemiluminescence.

Exclusion criteria: Age $>18$ years; pregnant and lactating women; women with chronic liver disease; women with renal disease.

\section{RESULTS AND DISCUSSION}

\section{Socio-Economic profile}

The socio-economic background of the women in the present study reflects a brief idea of their standards of living and socio-demographic drawbacks that might have a huge impact on their health and wellness. It is observed that the working women in the tea plantations mainly belonged to the age group of 18-40 years. 35.60 percent of the women are in the age group of 20-25 years, 29.20 percent are in the age group of 26-30 years, 20.40 percent are in the age group of 31-35 years, and 14.80 percent are in the age group of $36-40$ years. The women are daily wage earners of the tea estate. It is found that 53.20 percent of the women are outdoor workers engaged in field activities such as tea leaves plucking, pesticide spraying, gardening, and sweeping. The remaining 46.80 percent of the women are indoor workers and engaged in an occupation like ward girl, office peon, and cleaner. The monthly income of all the respondents (100\%) ranges from ₹ 4000-₹ 5000, which categorize them as a low socio-economic class. The average educational status of the women reflects a poor ratio, with 63.00 cents of the women being illiterate. The remaining 26.00 percent are literate below the primary school, 6.00 percent studied up to HSLC, and 5 percent are HSLC passed. It is further observed that 100 percent of the working women are married. 87.50 percent of the women married before 18 years, while 75 percent conceived before 18 years. 67.20 percent of the women had more than 2 children. Their family composition reveals that 55.6 percent of the women belonged to joint families, and 44.40 percent belonged to nuclear families. (Table 1).

\section{Vitamin D status of the women}

Assessment of vitamin D status is essential to determine the prevalence of vitamin $\mathrm{D}$ deficiency in individuals as vitamin D deficiency is asymptomatic. Outcomes of vitamin D deficiency such as osteoporosis and osteomalacia in adults and rickets in children are chronic and develop over a long period (Baig et al. 2013). The US Endocrine society (2011) categorizes a serum vitamin D value of $20 \mathrm{ng} / \mathrm{ml}$ to be expected. This value is accepted in most laboratories in India as the range given by them corresponds to most India populations and is considered an appropriate classification to determine vitamin D deficiency in the Indian population (Rani, 2014).

The serum vitamin $\mathrm{D}\left(1,25\right.$-dihydroxyvitamin $\left.\mathrm{D}_{3}\right)$ status assessment shows that 69.50 percent of the women have vitamin $\mathrm{D}$ deficiency with a mean serum vitamin D status of $18.50 \mathrm{ng} / \mathrm{ml}$ is below that standard normal range. Comparing the results in the different age groups, it is found that the prevalence of vitamin D deficiency 
is highest in the age group $36-40$ years $(45.9 \%)$. It is followed by the age group 31-35 years (35.2\%), 26-30 years $(31.4 \%)$ and $20-25$ years (25.8\%) (Fig. 1 ).

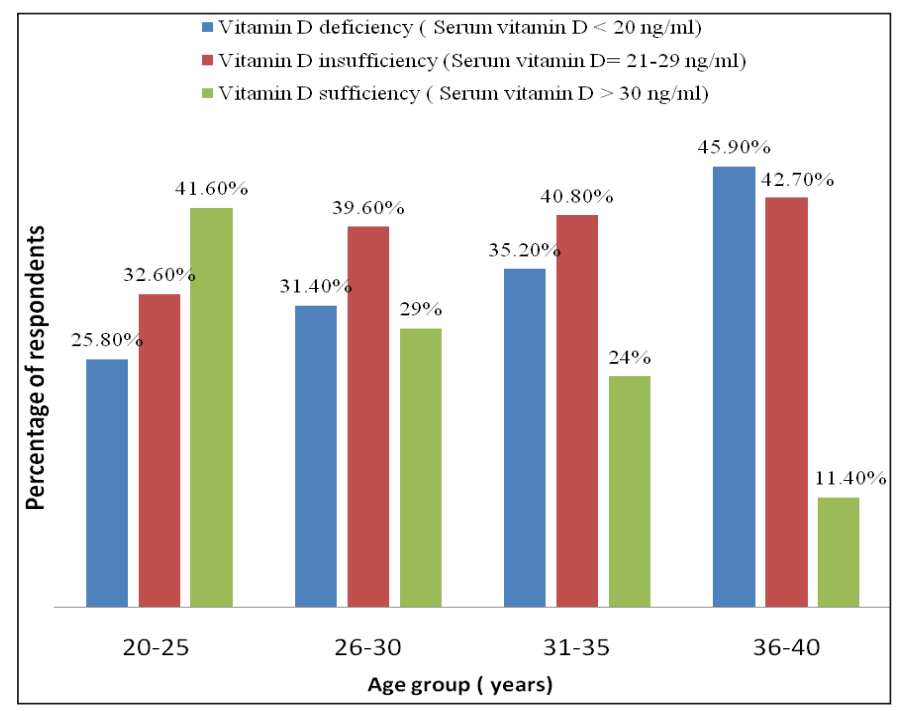

Fig. 1: Percentage distribution of respondents according to vitamin d deficiency as per classification by us endocrine society classification, 2011

Vitamin D deficiency is more prevalent among women in older age i.e. 36-40 years and 31-35 years. This is attributable to several age-related factors which exaggerate the poor vitamin D status among older women. With age, there is a decrease in the skin's ability to synthesize vitamin $\mathrm{D}$ as a result of decreased calcium absorption, intestinal resistance of calcium absorption to circulating $1,25(\mathrm{OH})_{2} \mathrm{D}$ decreased vitamin $\mathrm{D}$ receptors (VDR), and reduced kidney function, leading to decreased renal production of $1,25(\mathrm{OH})_{2} \mathrm{D}$ (Baily et al. 2014).

Several community-based and hospital-based research studies on the prevalence of vitamin D deficiency in India have shown a high prevalence rate of vitamin $\mathrm{D}$ deficiency among women in the reproductive age i.e., 18 to 45 years (Holick et al. 2011). In 2013, Agarwal et al. 2013 reported the prevalence of vitamin D in older women of more than 40 years (mean serum vitamin D $18.96 \mathrm{ng} / \mathrm{ml}$ ), which was contributed by reduced vitamin D metabolism influenced by aging. In 2018, Pereira et al. reported a high prevalence of vitamin D deficiency in women in the age group 35-50 years (69.94\%).

\section{Correlation of vitamin D with morbidity profile}

Morbidity profiles are essential in health studies as morbidity statistics reveal different disease conditions in a particular population (Azizeh et al. 2017). Morbidity rates in epidemiological studies are also useful in determining relationships between risk factors and disease conditions and thus helps plan and implement projects on future health-related challenges (Bachel et al. 2015).

On obtaining the morbidity profile of the women from the tea estate hospital records, it is found that the women are suffering from a range of chronic health ailments. 87.43 percent suffer from hypertension, 40 percent suffer from diabetes mellitus, 31.70 percent have cancer, 86.43 percent suffer from chronic body pain, and 42.70 percent have frequent episodes of chronic fatigue. It is also observed that the vitamin D status of the women suffering from the above-mentioned disease conditions has significantly lower $(\mathrm{p}<0.05)$ vitamin $\mathrm{D}$ status as compared to the healthy women (Table 2).

Studies conducted on vitamin D deficiency in chronic body pain reported that anomalies in bone mineralization resulting from prolonged vitamin $\mathrm{D}$ deficiency lead to softening of bone tissues, which further manifest as body pain (Gunjaliya et al. 2015). In 2018, Alsejari et al. reported that patients complaining of excessive daytime fatigue had lower levels of serum vitamin D (mean serum vitamin D $18.4 \mathrm{ng} /$ $\mathrm{mL}$ ). The study further recommended vitamin $\mathrm{D}$ supplementation of 80,000 IU weekly for 8 weeks and, after follow-up in 2 weeks, showed improvement in daytime fatigue and sleepiness. Vitamin D deficiency is associated with secondary elevation of parathyroid hormone, increased arterial resistance, and endothelial dysfunction leading to hypertension (Vaidya et al. 2010). In 2014, Tandon et al. conducted a study to assess the role of vitamin D deficiency in the development of essential hypertension and aggravation of its vascular complication and observed that serum vitamin D was statistically significantly lower in the hypertensive patient's group than in the control group. Vitamin $\mathrm{D}$ is associated with diabetes mellitus as it improves pancreatic $\beta$-cell function, decreases insulin resistance, 
Table 1: Socio-economic profile of the women in the tea plantations of Assam

\begin{tabular}{|c|c|c|c|c|c|}
\hline \multirow{2}{*}{$\begin{array}{l}\text { Sl. No. } \\
1\end{array}$} & \multirow{2}{*}{$\begin{array}{l}\text { Socio-economic parameter } \\
\text { Age }\end{array}$} & \multicolumn{4}{|c|}{ Response (in per cent) } \\
\hline & & 20-25 years & 26-30 years & 31-35 years & $36-40$ years \\
\hline & & 35.60 & 29.20 & 20.40 & 14.80 \\
\hline 2 & Occupation & \multicolumn{2}{|c|}{$\begin{array}{l}\text { Outdoor worker } \\
53.20\end{array}$} & \multicolumn{2}{|c|}{$\begin{array}{l}\text { Indoor worker } \\
46.80\end{array}$} \\
\hline 3 & Educational status & $\begin{array}{l}\text { Illiterate } \\
63.00\end{array}$ & $\begin{array}{l}\text { Below primary school } \\
26.00\end{array}$ & $\begin{array}{l}\text { Upto HSLC } \\
6.00\end{array}$ & $\begin{array}{l}\text { HSLC passed } \\
5.00\end{array}$ \\
\hline 4 & Marital status & \multicolumn{2}{|c|}{$\begin{array}{l}\text { Married before } 18 \text { years } \\
87.50\end{array}$} & \multicolumn{2}{|c|}{$\begin{array}{l}\text { Married after } 18 \text { years } \\
12.50\end{array}$} \\
\hline 5 & Childbirth & \multicolumn{2}{|c|}{$\begin{array}{l}\text { Before } 18 \text { years } \\
75.00\end{array}$} & \multicolumn{2}{|c|}{$\begin{array}{l}\text { After } 18 \text { years } \\
25.00\end{array}$} \\
\hline 6 & No. of children & \multicolumn{2}{|c|}{$\begin{array}{l}2 \text { or less than } 2 \\
32.80\end{array}$} & \multicolumn{2}{|l|}{$\begin{array}{l}\text { More than } 2 \\
67.20\end{array}$} \\
\hline 7 & Family composition & \multicolumn{2}{|l|}{ Joint family } & \multicolumn{2}{|c|}{ Nuclear family } \\
\hline & & 55.60 & & 44.40 & \\
\hline
\end{tabular}

Table 2: Mean serum vitamin D status of respondents in different morbidity

\begin{tabular}{llllll}
\hline Episodes & $\begin{array}{l}\text { Morbidity } \\
\text { present }(\%)\end{array}$ & $\begin{array}{l}\text { Mean serum vitamin D } \\
\pm \text { SD }(\mathbf{n g} / \mathbf{m l})\end{array}$ & $\begin{array}{l}\text { Morbidity } \\
\text { absent }(\%)\end{array}$ & \multicolumn{2}{l}{$\begin{array}{l}\text { Mean serum vitamin } \mathbf{D} \pm \\
\text { SD }(\mathbf{n g} / \mathbf{m l})\end{array}$} \\
\hline Body pain & 86.43 & $19.78 \pm 7.89$ & $13.57(34)$ & $36.76 \pm 4.13$ & $0.03^{*}$ \\
Chronic fatigue & 42.70 & $25.78 \pm 4.27$ & $57.30(143)$ & $30.57 \pm 4.98$ & $0.04^{*}$ \\
Hypertension & 87.43 & $18.97 \pm 4.56$ & $12.57(31)$ & $37.89 \pm 7.45$ & $0.01^{*}$ \\
Diabetes mellitus & 40.00 & $19.53 \pm 9.82$ & $60.00(150)$ & $23.65 \pm 3.24$ & $0.02^{*}$ \\
Cancer & 31.70 & $20.16 \pm 9.93$ & $68.30(171)$ & $36.42 \pm 6.30$ & $0.03^{*}$ \\
\hline
\end{tabular}

*significant at $p<0.05$.

and improves systemic inflammation (Rani, 2014). A retrospective study in South India showed 71.4 percent of the diabetic patients to be vitamin $\mathrm{D}$ deficient and 15 percent of the patients to be vitamin $\mathrm{D}$ insufficient, suggesting that vitamin $\mathrm{D}$ deficiency is highly prevalent among diabetic patients (Basil et al. 2013). Vitamin D is known to modulate gene expression, inhibit cellular proliferation, induction of differentiation, and apoptosis, ultimately inhibiting the cell growth of cancer. When prostate, colon, breast, lung and melanoma cancer cell lines are exposed to vitamin $\mathrm{D}$, growth inhibition occurs (Gallagher, 2013). An increased incidence of vitamin D deficiency $(80.4 \%)$ was observed in adult women from cancer compared to controls (Crowe et al. 2011).

\section{Correlation of vitamin D with sunning practice}

Sunning practices refer to the amount of time and body surface exposed to sunlight throughout the day. Vitamin
D deficiency is associated with exposure to sunning practice. Limited exposure to sunlight has consistently been identified as a primary contributing factor for vitamin D deficiency in many countries (Cashman et al. 2013).

The sun exposure pattern of the women in the tea plantations shows that $100 \%$ of the women exposed to the sun for more than 4 days per week show a mean vitamin D status of $19.05 \pm 6.34 \mathrm{ng} / \mathrm{ml}$ is below the normal range. $46.80 \%$ of the women who are exposed to the sun for 30 minutes to 1 hour show a mean vitamin D status of $18.95 \pm 7.11 \mathrm{ng} / \mathrm{ml}$, while $53.20 \%$ of the women who are exposed to the sun for more than 3 hours shows a mean vitamin D status of $19.87 \pm 5.98 \mathrm{ng} / \mathrm{ml}$. This indicates a prevalence of low vitamin D among the women in both the sun exposure duration. Further, on comparing the vitamin D status of the women with their clothing pattern, it is seen that their clothing pattern has 
Table 3: Mean vitamin D concentration of the women in accordance with sunning practices

\begin{tabular}{|c|c|c|c|}
\hline Variables & Categories & Mean vitamin D status $\pm \mathrm{SD}(\mathrm{ng} / \mathrm{ml})$ & $t$ ( $p$ value) \\
\hline \multirow[t]{3}{*}{ Sun exposure per week } & 1 day & - & - \\
\hline & 2 days & - & - \\
\hline & 4 or more days & $19.05 \pm 6.34$ & - \\
\hline \multirow[t]{2}{*}{ Sun exposure time per day } & 30 minutes- 1 hour & $18.95 \pm 7.11$ & \multirow{2}{*}{0.73} \\
\hline & More than 3 hours & $19.87 \pm 5.98$ & \\
\hline \multirow[t]{3}{*}{ Time of day spent outdoors } & $7 \mathrm{am}-10 \mathrm{am}$ & $19.67 \pm 1.25$ & \multirow{3}{*}{0.94} \\
\hline & $10 \mathrm{am}-1 \mathrm{pm}$ & $19.94 \pm 7.30$ & \\
\hline & $1 \mathrm{pm}-4 \mathrm{pm}$ & $19.45 \pm 5.16$ & \\
\hline
\end{tabular}

*significant at $p<0.05$.

a significant $(\mathrm{p}<0.05)$ impact on the women's vitamin $\mathrm{D}$ status. The mean vitamin D status of the women who follows a clothing pattern of saree with full-sleeved shirt with and without gloves were $19.62 \pm 6.40 \mathrm{ng} / \mathrm{ml}$ and $19.93 \pm 3.56 \mathrm{ng} / \mathrm{ml}$, respectively, which is below the normal range $(30 \mathrm{ng} / \mathrm{ml})$. The women who follow a clothing pattern of saree with short-sleeved blouses have a normal vitamin D status of $32.00 \pm 8.02 \mathrm{ng} / \mathrm{ml}$ (Table 3).

Despite long durations of sun exposure, the women in the tea plantations of Assam have low vitamin D status. The absorbance of vitamin $\mathrm{D}$ in their body is hindered by the women's clothing pattern. Being a part of a conservative society, these women cover the majority of their body parts which devoid their sun exposure. The disrupted absorbance of sunlight reduces the cutaneous synthesis of vitamin D in the body, which, for a prolonged time, leads to vitamin D deficiency. Vitamin D synthesis in the skin is dependent on the availability of UVB radiation to the skin, which is reduced by covering body surfaces such as hands and arms (Chaudhuri et al. 2013).

Harinarayan et al. (2009) reported a high prevalence of vitamin D deficiency among agricultural laborers exposed to sunlight for more than $4 \mathrm{~h}$ with only $15 \%$ of their body surface area exposed to sunlight. Similarly, lack of sun exposure as a result of covered clothing style was the most critical risk factor for low serum 25-hydroxyvitamin D in many countries in the Middle East (DeCourten et al. 2015).

\section{Correlation of vitamin D with tobacco and alcohol abuse}

Vitamin D deficiency is associated with tobacco and alcohol consumption as they have a significantly negative influence on vitamin D metabolism in the body (DeLuca, 2004). The women in the tea community are exposed a wrongfalse lifestyle choices because of their illiteracy and ignorance. Tobacco smoking and alcohol consumption are standard practices among them, which often pay a toll on their health. The majority of the women folk in the community depend on locally prepared tobacco and alcoholic drinks as a part of their daily beverage (Hagenau et al. 2009).

The mean vitamin D status of tobacco users and nontobacco users among the sample are $19.87 \pm 3.78 \mathrm{ng} / \mathrm{ml}$ and $32.65 \pm 8.93 \mathrm{ng} / \mathrm{ml}$, and for alcohol consumers and non-alcohol consumers were $19.67 \pm 5.43 \mathrm{ng} / \mathrm{ml}$ and $32.49 \pm 9.02 \mathrm{ng} / \mathrm{ml}$, respectively (Table 4 ). This is indicative that vitamin $\mathrm{D}$ statuses of tobacco and alcohol users are significantly $(p<0.05)$ lower than the normal range. 
Table 4: Mean vitamin D status of the women in accordance with tobacco and alcohol consumption

\begin{tabular}{llll}
\hline Variables & Categories & Mean 1,25-dihydroxy vitamin D \pm SD (ng/ml) & t (p value) \\
\hline Tobacco & Tobacco consumers & $19.87 \pm 3.78$ & $0.02^{*}$ \\
consumption & Non Tobacco consumer & $32.65 \pm 8.93$ & $0.04^{*}$ \\
\hline Alcohol & Alcohol consumer & $19.67 \pm 5.43$ & $32.49 \pm 9.02$ \\
\hline
\end{tabular}

*Significant at $p<0.05$.

Consumption of alcohol and tobacco has a severe impact on the liver and hampers its functioning, which for a prolonged time also affects the kidney. Vitamin $\mathrm{D}$ metabolism in the body is dependent on the liver and kidney. The liver and kidney are the major sites of conversion of the active form of vitamin D in the body. Any disruption in their functioning reduces vitamin $\mathrm{D}$ activation and utilization resulting in a lower concentration of 1,25-dihydroxy vitamin D (Heaney et al. 2011). In 2015, Junaid et al. reported the prevalence of vitamin D deficiency in Australian adults who were regular smokers and alcoholics. In 2017, Kaddam et al. reported a high prevalence rate of vitamin D deficiency in an adult Chinese population who were involved in tobacco and alcohol abuse for a long time, resulting in damaged liver and kidney functioning.

\section{Correlation of vitamin D with dietary intake}

Diet contributes to the regulation of vitamin D concentration in the body. Adequate dietary intake of vitamin $D$ increases vitamin D stores in the body, making it available for the various metabolic processes in the body. Calcium intake improves vitamin D absorption in the intestine and maintains serum vitamin D levels (Holick, 2017).

The intake of vitamin D and calcium-rich food among the women is assessed to correlate dietary intake and vitamin D deficiency. A significant positive correlation between 1,25-dihydroxy vitamin $\mathrm{D}$ status and dietary intake of vitamin D and calcium is observed (Table 5). This indicates that the lower dietary intake is a strong contributor to vitamin D deficiency among the women in the tea plantations.

The women in the tea plantations are adapted to poor nutrition as a result of their low income. This disables their purchasing capacity, due to which they cannot afford food such as milk and milk products, eggs, meat and so on. The lack of knowledge and awareness among them also prohibits their accessibility to the utilisation of the available resources for their health and nutrition. Other factors such as larger family composition and disparity in food distribution within the family prohibit the good share of food and nutrients for the women.

Table 5: Correlation of 1, 25-dihydroxyvitamin D status of the respondents with dietary intake of vitamin $\mathrm{D}$ and calcium

\begin{tabular}{lll}
\hline S1. No. & Dietary intake & Correlation coefficient \\
\hline 1 & Dietary vitamin D & $+0.414^{* *}$ \\
2 & Dietary calcium & $+0.209^{*}$ \\
\hline
\end{tabular}

** significant at $p<0.01,{ }^{*}$ significant at $p<0.05$.

A similar association of serum vitamin D and dietary inadequacy of vitamin $\mathrm{D}$ and calcium was reported by Goowalla et al. (2012) among rural women in Northern India. It was further observed that low affordability led to lower dietary intake of vitamin D and calcium, which led to lower vitamin D status among the population. In 2014, Ritu et al. reported a lower intake of calcium affects vitamin $\mathrm{D}$ absorption in the intestines, leading to vitamin D deficiency. In 2018, Harinarayan et al. reported a high prevalence of vitamin D deficiency in the Indian population resulting from low dietary intake of vitamin $\mathrm{D}$ and inadequate calcium intake (below the recommended dietary allowance for that particular age group).

The present study highlights the prevalence of vitamin $\mathrm{D}$ among women in the tea plantations of Assam. The clothing pattern of the women, which is seen to cover most parts of their bodies, is observed to be a significant 
factor that contributes to the low vitamin D status among the women. The majority of the women are accustomed to regular tobacco and alcohol consumption, mainly in the locally prepared forms. This lifestyle practice has been a severe threat to their liver and kidney functioning, thereby significantly reduces their vitamin D status. Further, the dietary intake of the women is strongly devoid of vitamin D and calcium. This factor gravely affects their vitamin D stores and hinders its absorbance in the body. The study has also identified the association of vitamin D deficiency with existing disease conditions prevailing among the women viz., hypertension, diabetes mellitus, cancer, chronic fatigue, and body pain.

\section{CONCLUSION}

The present study has identified clothing patterns, tobacco, and alcohol consumption, and low intake of dietary sources of vitamin $\mathrm{D}$ and calcium to be the major contributor of vitamin D deficiency among women. Despite prolonged sun exposure, women are affected by vitamin D deficiency. Hence, the paradigm entailing the mere dependence on the cutaneous synthesis for adequate vitamin $\mathrm{D}$ does not stand true as vitamin $\mathrm{D}$ deficiency has been recognized in a large number of countries with adequate sunshine. A perusal of several studies have shown lifestyle practices, availability of vitamin $\mathrm{D}$ rich foods, mandatory vitamin $\mathrm{D}$ fortification of the foods, vitamin D supplementation programs, reduced environmental pollution, and availability of inexpensive and accessible diagnosis of vitamin D status would be helpful in mitigating the gravity of the prevalence of vitamin D deficiency.

The women working in the tea plantations are a prominent part of the tea industry and thereby contribute to the state and nation's economy as well. Their health and wellness are of significance to society. The existence of vitamin D deficiency among them is a potential threat to their overall health, which might pave the way for chronic skeletal and non-skeletal disorders. In the long run, this would create a major drawback to their productivity and working ability. Therefore, it is the need of the hour to bring this epidemic to light and work for its eradication. It is necessary to e the tea community regarding the significance of vitamin D and how to utilize it through the available resources. Furthermore, it is the peak time to make them aware of their faulty lifestyle practices to stop the deterioration of their health.

\section{REFERENCES}

Afzal, S.; Bojesen, S.E. and Nordestfaard, B.G. 2013. Low 25-Hydroxyvitamin D and risk of type 2 Diabetes: a prospective cohort study and meta-analysis. Clin. Chem., 59: 381-391.

Agarwal, N.K. and Sharma, B. 2013. Prevalence of osteoporosis in otherwise healthy Indian males aged 50 years and above. Arch Osteoporos, 8: 116.

Ahasan, H.N. and Das, A. 2013. Vitamin D deficiency in South Asian populations: A serious emerging problem. J. Enam. Med. Coll., 3: 63-66.

Alsejari, M.M. 2018. Prevalence and Risk Factors of Vitamin D Deficiency among a Sample of Kuwaiti Population: A Sociocultural Study. Coll. Antropol., 42(2): 73-83.

Azizieh, F.Y., Alyahya, K.O. and Dingle, K. 2017. Association of self-reported symptoms with serum levels of vitamin D and multivariate cytokine profile in healthy women. J. Inflamm. Res., 10: 19-28.

Bachel, R., Singh, N.R. and Sidhu, J.S. 2015. Prevalence of Vitamin D deficiency in North-west Punjab population: A cross sectional study. Int. J. Appl. Basic Med. Res., 5: 7-11.

Baidya, A., Chowdhury, S., Mukhopadhyay, S. and Ghosh, S. 2012. Profile of vitamin D in a short of physicians and diabetologists in Kolkata. Indian J. Endocrinol Metab., 16: 416-417.

Baig, J.A., Sheikh, S., Islam, I. and Kumar, M. 2013.Vitamin D status among Vegetarians and Non-vegetarians. J. Ayub Med. Coll. Abbottabad, 25: 152-155.

Baily, D., Perumal, N. and Yazdanpanah, M. 2014. Maternal-fetal dynamics of the c3-epimer of 25-hydroxyvitamin D. Clin. Biochem., 47: 816-822.

Baishya, D. 2016. History of tea industry and status of tea garden workers of Assam. Int. J. Appl. Res., 2(9): 552-556.

Basil, D., Rahme, M., Hoteit, M. and Fuleihan, G.H. 2013. Hypovitaminosis D in the Middle East and North Africa: Prevalence, risk factors, and impact on outcomes. Dermatoendocrinol, 5(2): 274-98.

Bawaskar, P.H., Bawaskar, H.S., Bawskar, P.H. and Pakhare, A.P. 2017. Profile of Vitamin D in patients attending at general hospital Mahad India. Indian J. Endocr. Metab., 21: 125-30.

Cashman, K.D., Kiely, M. and Kinsella, M. 2013. Evaluation of vitamin D standardization program protocols for standardizing serum 25-hydroxyvitamin D data: a case study of the 
program's potential for national nutrition and health surveys. Am. J. Clin Nutr., 97: 1235-1242.

Chaudhuri, J.R., Mridula, K.R., Anamika, A., Boddu, D.B., Mishra, P.K., Lingaiah, A., Balaraju, B. and Bandaru, V.S. 2013. Deficiency of 25-hydroxyvitamin D and dyslipidemia in Indian subjects. J. Lipid., 623420: 1-7.

Chirumbolo, A. 2015. Vitamin D3 in cancer prevention and therapy: the nutritional issue. Horm. Mol. Biol. Clin. Investig., 23(5): 71-78.

Chowdhury, R., Taneja, S., Bhandari, N., Sinha, B., Upadhyay, R.P. and Bhan, M.U. 2017. Vitamin D deficiency predicts infections in young North Indian children: A secondary data analysis. PLOS ONE, 12(3): 1-12.

Crowe, F.L., Steur, M., Allen, N.E., Appleby, P.N., Travis, R.C. and Key, T.J. 2011. Plasma concentrations of 25-hydroxyvitamin $\mathrm{D}$ in meat eaters, fish eaters, vegetarians and vegans: results from the EPIC-Oxford study. Pubic Health Nutr., 14: 340-346.

Daly, R.M., Gagnon, C., Lu, Z.X., Magliano, D.J., Dunstan, D.W., Sikaris, K.A. and Zimmet, P.Z. 2012. Prevalence of vitamin $\mathrm{D}$ deficiency and its determinants in Australian adults aged 25 years and older: a national, population-based study. Clin. Endocri., 77: 26-35.

DeCourten, B., Mousa, A., Naderpoor, N., Teede, H., deCourten, M. and Scragg, R. 2015. Vitamin D supplementation for the prevention of type 2 diabetes in overweight adults: study protocol for a randomized controlled trial. Trials., 16(1): 335346.

DeLuca, H.F. 2004. Overview of general physiologic features and functions of vitamin D. Am. J. Clin. Nutr., 80: 1689-1696S.

Forrest, K.Y. and Stuhldreher, W.L. 2011. Prevalence and correlates of vitamin D deficiency in US adults. Nutr. Res., 31: 48-54.

Gallagher, J.C. 2013. Vitamin D and Aging. Endocrin. Metab. Clin. North Am., 42: 319-332.

Garg, M.K., Tandon, N., Marwaha, R.K., Menon, A.S. and Mahalle, N. 2014. The relationships between serum 25-hydroxyvitamin $\mathrm{D}$, parathoromone and bone mineral density in Indian population. Clin. Endocrinol., 80: 41-46.

Goowalla, H. 2012. Labour Relations Practices in Tea Industry of Assam- With Special Reference to Jorhat District of Assam, IOSR Journal of Humanities and Social Science, pp. 35-41.

Gunjaliya, A., Patil, R., Vaza, J., Patel, H. and Maniyar, A. 2015. Prevalence of Vitamin D deficiency in higher socio-economic class of Ahmedabad, Gujarat, India. Int. J. Med. Sci. Public Health., 4: 617-20.

Gunjaliya, A., Patil, R., Vaza, J., Patel, H. and Maniyar, A. 2015. Prevalence of Vitamin D deficiency in higher socio-economic class of Ahmedabad, Gujarat, India. Int. J. Med. Sci. Public Health, 4: 617-20.
Hagenau, T., Vest, R., Gissel, T.N., Poulson, C.S., Erlandsen, M., Moseklide, L. and Vestergaard, P. 2009. Global Vitamin D levels in in relation to age, gender, skin pigmentation and latitude: an Ecologic meta- regression analysis. Osteoporosis Int., 20: 133-140.

Harinarayan, C.V. 2018. How to treat Vitamin D deficiency in sun-drenched India - guidelines. J. Clin. Sci. Res., 7: 131-40.

Harinarayan, C.V. and Joshi, S.R. 2009. Vitamin D status in IndiaIts implications and and remedial measures. J. Assoc. Physicians India, 57: 40-48.

Harsh, A., Nidhi, S. and Kumud, B. 2016. Prevalence of Vitamin D/B12 deficiency among urban populations complaining pain of lower limb and generalise weakness. Asian J. Pharm. Clin. Res., 9: 261-263.

Heaney, R.P., Recker, R.R., Grote, J., Horst, R.L. and Armas, L.A. 2011. Vitamin D(3) is more potent than Vitamin $D(2)$ in humans. J. Clin. Endocrinol. Metab., 96: 447-452.

Holick, M.F., Binkley, N.C. and Bischoff-Ferrari, H.A. 2011. Evaluation, treatment and prevention of vitamin D deficiency. An Endocrine Society Practice Guideline. J. Clin. Endocrin. Metab., 96: 1911-1930.

Holick, M.F. 2017. The vitamin D deficiency pandemic: approaches for diagnosis, treatment and prevention. Reviews in Endocrine and Metabolic Disorders, 18: 153-165.

Hossein-nezhad, A. and Holick, M.F. 2013. Vitamin D for health: a global perspective. In. Mayo Clinic Proceedings, 88(7): 720-755.

Institute of Medicine, Food and Nutrition Board. 2011. Dietary Reference Intakes for Calcium and Vitamin D, National Academies Press., Washington, DC.

Jiang, C.Q., Chan, Y.H., Xu, L., Jin, Y.L., Zhu, T., Zhang, W.S., Cheng, K.K. and Lam, T.H. 2016. Smoking and serum vitamin $\mathrm{D}$ in older Chinese people: cross- sectional analysis based on the Guangzhou Biobank Cohort Study. BMJ Open, 6: e010946.

Junaid, K., Rehman, A., Jolliffe, D.A., Wood, K. and Martineau, A.R. 2015. High prevalence of vitamin D deficiency among women of child-bearing age in Lahore Pakistan, associating with lack of sun exposure and illiteracy. BC Women's Health, 15: 83.

Kaddam, I.M., Al-Shaikh, A.M. and Abaalkhail, B.A. 2017. Prevalence of vitamin D deficiency and its associated factors in three regions of Saudi Arabia. Saudi Med. J., 38(4): 381-390.

Lee, H., Kim, K.N., Lim, Y.H. and Hong, Y.C. 2015. Interaction of Vitamin D and smoking on inflammatory markers in the urban elderly. J. Prev. Med. Public Health, 48: 249-256.

Marangi tea estates of Assam, India. Int. Multidisciplinary J., pp. 129-1.

Pereira- Santos, M., Costa, P.R., Assis, A.M., Santos, C.A. and Santos, D.B. 2015. Obesity and vitamin D Deficiency: a systemic review and meta-analysis. Obes. Rev., 16: 341-349. 
Rani, S. 2014. Confusions in Vitamin D Estimation and Interpretation. IOSR J. Pharm. Biol. Sci., 9(3): 14-20.

Rattan, R., Sahoo, D. and Mahapatra, S. 2016. Prevalence of vitamin $\mathrm{D}$ deficiency in adults in the coastal regions of Odisha, India. IOSR J. Pharm. Biol. Sci., 11: 49-52.

Ritu, G. and Gupta, A. 2014. Vitamin D deficiency in India: Prevalence, causalities and interventions. Nutrients, 6: 729-775.

Tandon, V.R., Sharma, S., Mahajan, S., Raina, K., Mahajan, A. and Khajura, V. 2014. Prevalence of vitamin D deficiency among Indian menopausal women and its correlation with diabetes: A first Indian cross sectional data. J. Midlife Health, 5: 121-5.
Vaidya, A. and Forman, J.P. 2010. Vitamin D and hypertension: current evidence and future directions. Hypertension, 56: 774779 .

Vitamin D status and bone mineral density in women of reproductive and post-menopausal age groups: A crosssectional study from South India. J. Assoc. Physicians India, 59: 698-704.

Wacker, M. and Holick, M.F. 2013. Sunlight and Vitamin D: A global perspective for health. Dermatoendocrinol, 5(1): 51-108. 